\title{
Distraction Display by Western Meadowlark
}

by Robert W. Nero, Saskatchewan Museum of Nature History.

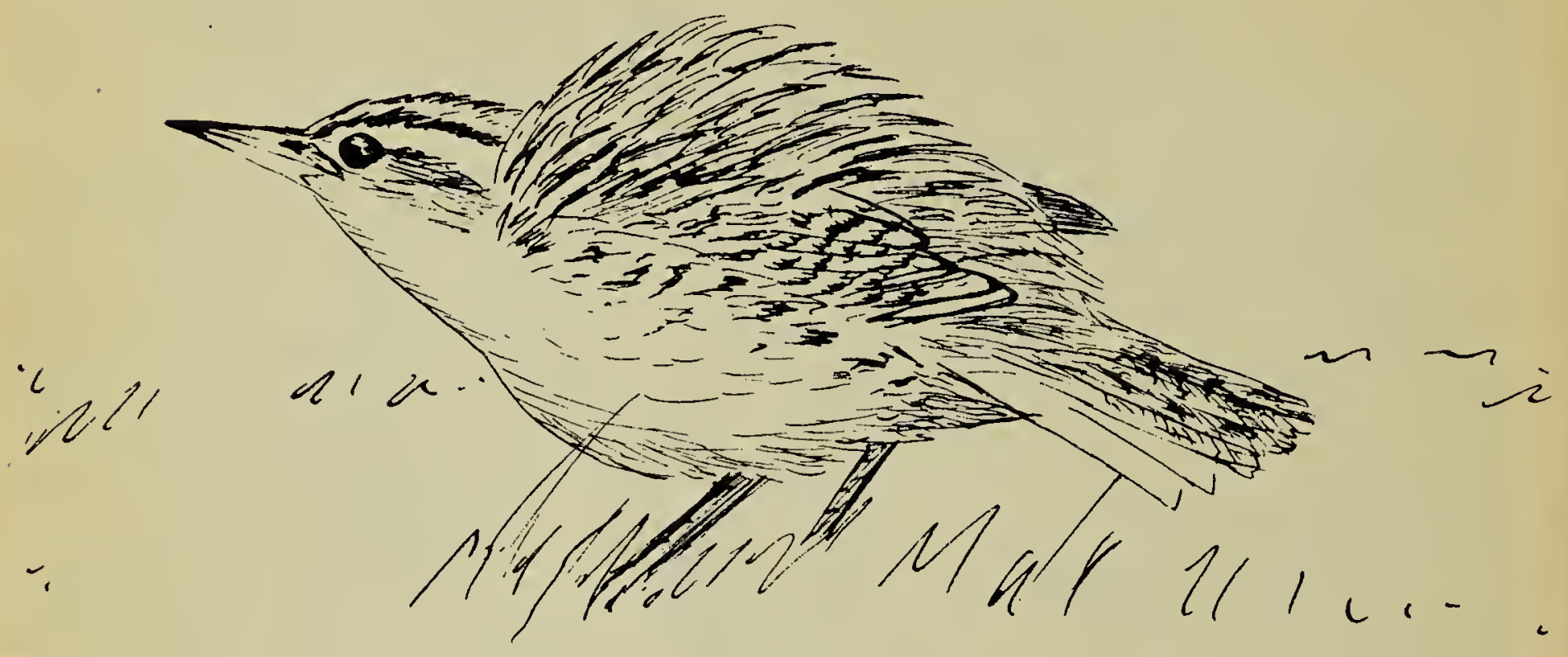

Sketch by Fred W. Lahrman

Distraction display or "injury feigning," i.e. the "broken-wing act," occurs regularly among some species of birds when disturbed at the nest, for example the Killdeer (Oxyechus vociferus), but it is irregular or uncommon or even unknown in certain others. It has been recorded in the Icteridae only a few times for the Eastern Meadowlark (Sturne l la magna), the Western Meadowlark (Sturnella neglecta) and the Bobolink (Dolichonyx oryzivorous), according to information received from Frederick V. Hebard, Philadelphia, who has long been interested in this behaviour pattern. Dr. Wesley E. Lanyon, assistant curator of birds, American Museum of Natural History, who has specialized in a study of meadowlarks, writes: "I . . . have never personally witnessed it, though I've certainly had plenty of opportunity to do so if such a behaviour pattern were commonplace." (Personal correspondence, September, 1958). During the past ten years during which I have been studying the Redwinged Blackbird (Agelaius phoeniceus) and other icterids, I have observed this behaviour once in the Bobolink and recently at two nests of the Western Meadowlark.

On May 18,1956 , at 6.20 a.m. C.S.T. a Western Meadowlark, presumably a female, was observed giving distraction display after being flushed from a nest containing five eggs. The nest was located on open grazed prairie within the city limits in northwest Regina. According to my notes made at the time, the bird ran or hopped rapidly along on the ground with head lowered, wings and tail stiffly outspread and touching the ground throughout the display. Unfortunately, I did not take time to record the state of incubation.

This year (1959) on June 4, at about 8.00 p.m., Fred W. Lahrman observed distraction display given by a female Western Meadowlark flushed from a nest on heavilygrazed pasture land near Wascana Creek in Regina. The nest contained two newly-hatched young and two eggs. A third egg, which was pipped and contained a dead chick, lay outside the nest. The bird flushed at about five feet and fluttered away from the nest low over the ground straight away for about 20 feet (possibly touching the ground). It then hopped rapidly along the ground in an erratic course in a peculiar hunched posture with the feathers of the back raised and the head held low and the wings closed (see sketch), and then it suddenly flew away.

I went out the following morning 
(June 6), arriving at the nest at about 5.15 a.m. The female, which had been brooding four young, flushed from the nest when I was five feet away. She flew off fast and low, just above the short grass, for some 15 feet, then dropped to the ground and ran rapidly straight away from me, dodging in between short clumps of grass, for about 100 yards. During this amazingly long run I watched her with binoculars and noted that the bird was in a hunched position all the time, with head lowered, and seemingly crouching low. The feathers of the back were raised and the tail was spread on the left side only, so that the left white tail pattern was clearly visible. At one time during the run, as the bird reached an open area of nearly bare ground, she raised the folded right wing slightly, but only morientarily. When about 100 yards away she was joined by the male which silently walked toward her, and which appeared to thrust hard at the ground once or twice with its beak, I think, in a gaping movement (displacement feeding?) The female finally stopped and ruffled up her feathers, a common comfort movement following intense behaviour, and my observations were then discontinued.

Miss Joyce Dew visited the nest on June 8 at 8.00 p.m. and the female flushed from the nest at about 30 feet, flying low and quickly away from the nest. At this time there was only one young in the nest. (We have no clues to the whereabouts of the other three.)

In an attempt to record distraction behaviour of the meadowlark on film $I$ visited the nest accompanied by Fred Lahrman and Richard Fyfe at about 5.00 a.m. on June 9. This time the female flushed when we were about 40 feet from the nest She slipped out of the nest and at once, hunched and crouching, scurried rapidly away for about 30 yards-long before our cameras were set up! On June 12 the nest was empty and apparently deserted.

It is clear that distraction display is rare in the Icteridae, but even though a behaviourism may have been observed only once or twice, if it occurs at all it is a part of the total behaviour pattern of a species. The low frequency of occurrences in icterids may be due to the seemingly greater aggressiveness of these birds.
Distraction display is considered to be the result of conflict between tendencies to escape and attack. That is, a bird flushed from a nest seeks to escape but still, to some extent. is motivated (or wants) to protect the nest. Redwings, for example, seldom fly far from the nest when disturbed and it may be that in this species escape tendencies are so much lower than attack tendencies that conflict between these drives is lacking, and consequently no distraction display is given. The Bobolink and the meadowlarks (both ground-nesters), it seems to me, are less aggressive at the nestsite, i.e. escape tendencies are much stronger than attack tendencies. The occasional appearance of this display in these species may be due to moments of higher attack or lower escape tendencies. According to Simmons (see below) various types of "predator reactions" are known for certain species which have been well observed and these behaviourisms are thought to occur at different levels of conflict. At one level, the full distraction display occurs. The few observations recorded for the meadowlarks may represent moments of conflict due to a balance between escape and attack tendencies, possibly linked to a particular state of incubation and a time when the incubating bird is reluctant to leave the eggs or young, the conflict being between fleeing and staying. Less noticeable displays under ordinary conditions of low conflict may be overlooked. Fred W. Lahrman has pointed out to me that it is his impression that meadowlarks flushed from the nest frequently fly low for several yards before rising, sometimes striking vegetation with their wings. Movies of this behaviour might show more clearly elements of distraction display which are otherwise difficult to discern.

British ornithologist K. E. L. Simmons has paid considerable attention to distraction display, which he defines as fcrms of conspicuous ritualized behaviour releasing and directing hunting behaviour in a predator (1955. The nature of the predatorreactions of Waders towards humans; with special reference to the role of the aggressive -, escape -, and brooding drives. Behaviour, Vol. 8, Part .2-3; 130-173). Simmons states that the full form of distractiondisplay is due to an intense. conflict between escape and attack, with a 
high aggressive content related to the parental-drive. Simmons conducted a large number of experiments with -waders to elicit predator-reactions. Among other interesting things he found that most species showed far less fear toward a human lying down than to one standing. He points to a need for objective methods of in- vestigation and interpretation in the study of predator-reactions and indicates a need for precise work on individual species.

I should like to thank Dr. Frank McKinney, Delta Waterfowl Research Station, for critical examination of this note and for calling my attention to the work by Simmons.

\section{Great Horned Owl Distraction Display}

by R. W. Fyfe, Saskatchewan Museum of Natural History.

Predatory birds rarely exhibit any form of distraction display or "injury feigning" when their nests are approached. Bent (Life Histories of North American Birds of Prey, Vol. II) indicated that such display is exhibited only occasionally by predatory - species - other than the Long-eared Owl (Asio otus) in which it occurs regularly. On two separate occasions, May 14 and June 3, 1959, I witnessed distraction display by a Great Horned Owl (Bubo virginianus) when we visited the nest. On May 14 when we approached the nest, which then contained two newly-hatched young, both parents flew to the opposite hillside about 100 yards distant and remained standing on the ground continually hooting and screaming as we approached the nest. Then one bird suddenly began walking slowly, alternately dragging and flopping its right wing on the ground. At the same time, presumably the same bird began to utter most un-owl-like screams. This display continued for a short period while the bird moved about twenty feet over the ground; the bird then stood still though occasionally screaming as before. On our second visit, the birds behaved as before except that when flying to the hillside, one bird suddenly fell into low brush as if it had been shot. A moment later it reappeared, walking and dragging its wing as before, all the while uttering the same cry of distress. In each case, the display had lasted only while we were in the immediate vicinity of the nest.

\section{Great Horned Owl Banding}

by Stuart Houston, Yorkton.

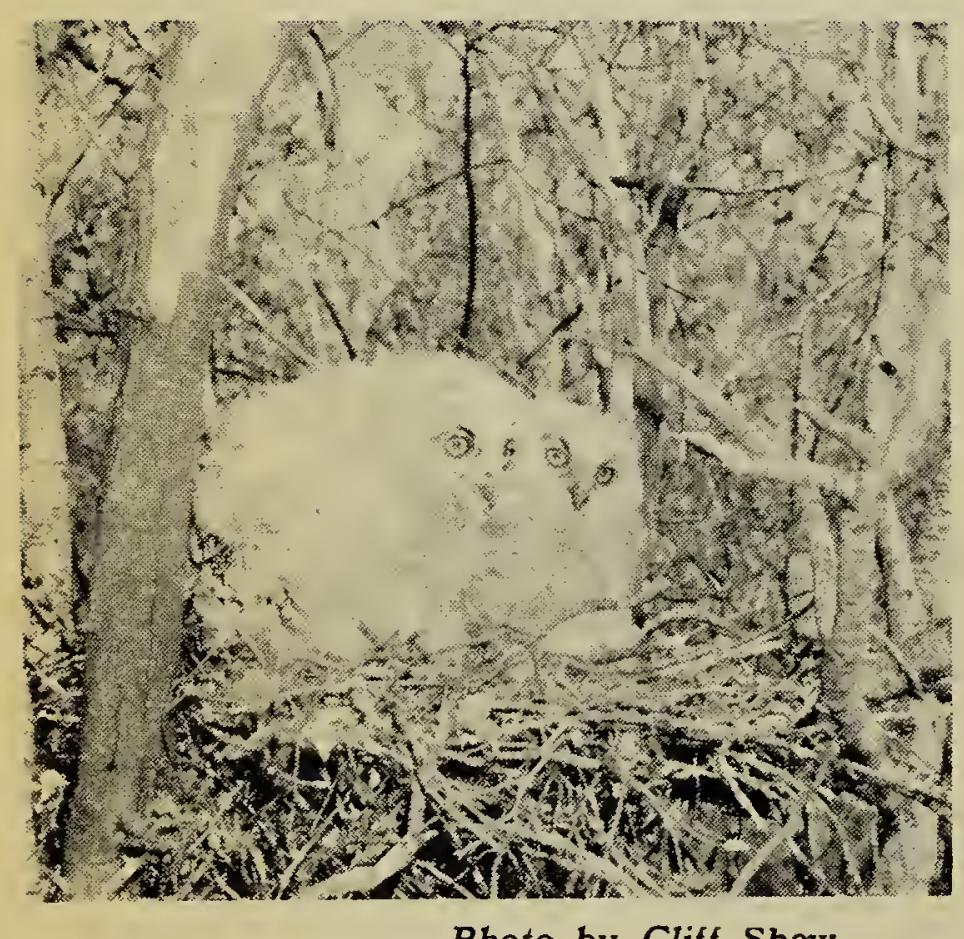

Photo by Cliff Shaw

Young Great Horned Owls in nest

Our 1958 owl banding (22 young in 10 nests) was considered worthy of mention as "a fine example of field work" in the continent-wide summary of nesting records in the October 1958 issue of Audubon Field Notes. But my enthusiastic helper, Bill Horseman, was still not satisfied and determined that we should set a new record in 1959.

Sunday, May 17, was planned as the "big day" and we started out at 5 a.m. for the Saltcoats district. Horseman knew of ten nests and an additional eight had been located by patients of mine. We were encouraged to find that only one nest had been deserted and none destroyed, of the eighteen nests we visited that day. The residents of this area seem more tolerant of owls than they were in the past.

The number of young raised to maturity is often a fairly good index of the food supply; judging by this the owls had a good year. One nest contained four young ready to leave the nest, eight nests had three young 